ADA groups, while herpes zoster, lymphopenia, hepatic disorder, and CPK elevation were reported at higher rates with UPA. Consistent with earlier time points, greater proportions of patients randomized to UPA achieved low disease activity and remission at 3 years based on CDAl, as well as DAS28(CRP) $\leq 3.2$ or $<2.6$, compared with patients randomized to ADA (Table 1).

Conclusion: The safety profile of UPA was consistent with the results reported previously and with the integrated Phase 3 safety analysis. ${ }^{1,2}$ Higher levels of clinical response continued to be observed with UPA vs ADA through 3 years of treatment.

REFERENCES:

[1] Fleischmann R, et al. Ann Rheum Dis 2020;79:323.

[2] CohenSB, etal.AnnRheum Dis2020; doi:10.1136/annrheumdis-2020-218510.

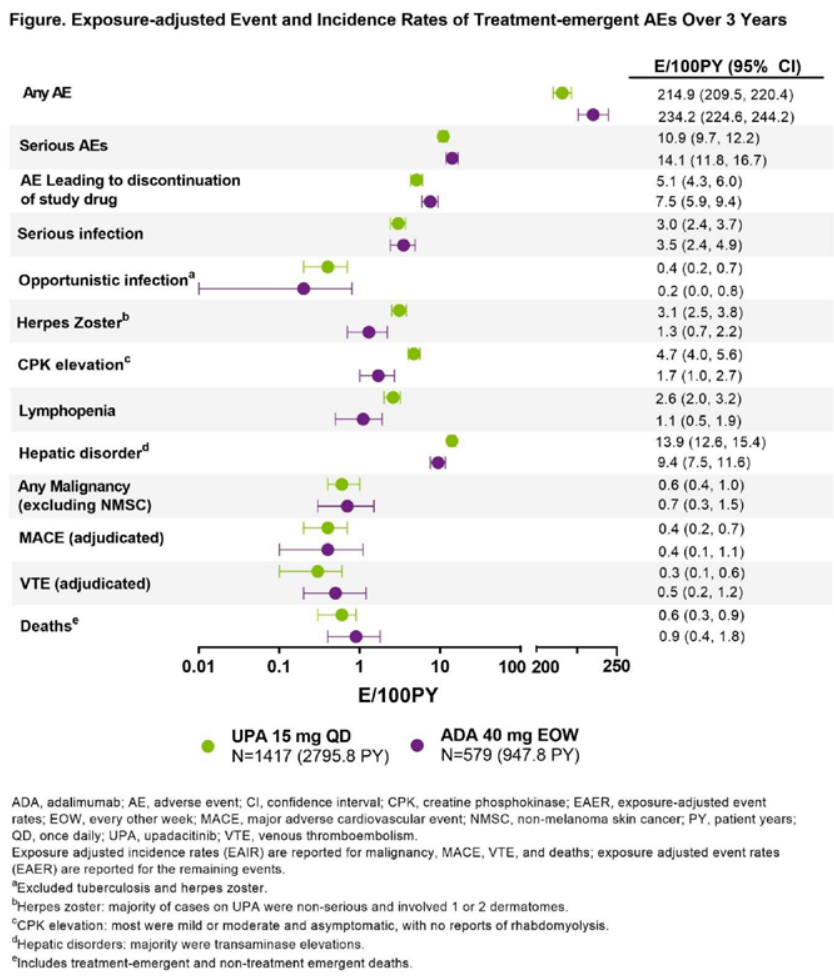

Table 1. Efficacy Endpoints at 3 Years (NRI)

\begin{tabular}{|c|c|c|}
\hline Endpoints, \% (95\% Cl) & $\begin{array}{l}\text { UPA } 15 \mathrm{mg} \text { QD } \\
\qquad \mathrm{N}=651^{*}\end{array}$ & $\begin{array}{c}\text { ADA } 40 \mathrm{mg} \text { EOU } \\
\qquad \mathrm{N}=327^{*}\end{array}$ \\
\hline $\begin{array}{l}\text { CDAI } \leq 10 \\
\text { CDAI } \leq 2.8 \\
\text { DAS28(CRP) } \leq 3.2 \\
\text { DAS28(CRP) }<2.6\end{array}$ & $\begin{array}{l}39(36,43) \\
24(21,28) \\
37(33,41) \\
32(29,36)\end{array}$ & $\begin{array}{l}29(24,34) \\
17(12,21) \\
26(21,31) \\
22(17,26)\end{array}$ \\
\hline \multicolumn{3}{|c|}{$\begin{array}{l}\text { ADA, adalimumab; Cl, confidence interval; DAS28(CRP), Disease Activity Score for } 28 \text {-joints } \\
\text { C-Reactive Protein; CDAI, clinical disease activity index; EOW, every other week; NRI, } \\
\text { non-responder imputation; QD, once daily; UPA, upadacitinib.*Patients who were rescued } \\
\text { prior to/at Week } 26 \text { were considered non-responders. } 252 / 651 \text { and } 159 / 327 \text { patients were } \\
\text { rescued of those randomized to UPA and ADA, respectively. }\end{array}$} \\
\hline
\end{tabular}

Acknowledgements: AbbVie and the authors thank the patients, trial sites, and investigators who participated in this clinical trial. AbbVie, Inc was the trial sponsor, contributed to trial design, data collection, analysis \& interpretation, and to writing, reviewing, and approval of final version. No honoraria or payments were made for authorship. The authors thank Dr. Tim Shaw of AbbVie Inc. for his support with the interpretation of the data. Medical writing support was provided by Ramona Vladea, PhD, of AbbVie, Inc.

Disclosure of Interests: Roy Fleischmann Consultant of: AbbVie, Amgen, Bristol-Myers Squibb, Eli Lilly, GSK, Janssen, Novartis, Pfizer Inc, Sanofi-Aventis, and UCB, Grant/research support from: AbbVie, Amgen, Boehringer Ingelheim, Bristol-Myers Squibb, Celgene, Eli Lilly, Genentech, Janssen, Novartis, Pfizer Inc, Regeneron, Roche, Sanofi-Aventis and UCB, Eduardo Mysler Consultant of: AbbVie, AstraZeneca, Lilly, Pfizer, Roche, BMS, Sandoz, GSK, Janssen, Grant/research support from: AbbVie, AstraZeneca, Lilly, Pfizer, Roche, BMS, Sandoz, GSK, Janssen, Louis Bessette Consultant of: Amgen, BMS, Janssen, Roche, UCB, AbbVie, Pfizer, Merck, Celgene, Sanofi, Eli Lilly, Novartis, Gilead, Grant/research support from: Amgen, BMS, Janssen, Roche, UCB, AbbVie,
Pfizer, Merck, Celgene, Sanofi, Eli Lilly, Novartis, Gilead, Charles Peterfy Shareholder of: Spire Sciences, Inc, Speakers bureau: Amgen, Bristol-Myers Squibb Consultant of: Aclaris, Centrexion, Daiichi Sankyo, EMD, Serono, Five Prime Flexion Therapeutics, Genentech, Gilead, GlaxoSmithKline, Istresso, Eli Lilly, Myriad Genetics, Novartis, Roche, SetPoint, Sorrento, UCB, Employee of: Spire Sciences, Inc, Patrick Durez Speakers bureau: BMS, Sanofi, Eli Lilly, Celltrion, Yoshiya Tanaka Speakers bureau: Daiichi-Sankyo, Astellas, Chugai, Eli Lilly, Pfizer, AbbVie, YL Biologics, Bristol-Myers, Takeda, Mitsubishi-Tanabe, Novartis, Eisai, Janssen, Teijin, Consultant of: Daiichi-Sankyo, Astellas, Chugai, Eli Lilly, Pfizer, AbbVie, YL Biologics, Bristol-Myers, Takeda, Mitsubishi-Tanabe, Novartis, Eisai, Janssen, Teijin, Grant/research support from: Asahi-kasei, Mitsubishi-Tanabe, Chugai, Takeda, Sanofi, Bristol-Myers, UCB, Daiichi-Sankyo, Eisai, Ono, Jerzy Swierkot Speakers bureau: AbbVie, Sandoz, Pfizer, Roche, BMS, UCB, MSD, Accord, Janssen, Consultant of: AbbVie, Sandoz, Pfizer, Roche BMS, UCB, MSD, Accord, Janssen, Grant/research support from: AbbVie, Sandoz, Pfizer, Roche, BMS, UCB, MSD, Accord, Janssen, Nasser Khan Shareholder of: AbbVie, Employee of: AbbVie, Xianwei Bu Shareholder of: AbbVie, Employee of: AbbVie, Yihan Li Shareholder of: AbbVie, Employee of: AbbVie, In-Ho Song Shareholder of: AbbVie, Employee of: AbbVie.

DOI: 10.1136/annrheumdis-2021-eular.535

\section{POS0088 EFFICACY OF JANUS KINASE INHIBITORS FOR DIFFICULT-TO-TREAT RA IN CLINICAL PRACTICE}

M. Kamiya ${ }^{1}$, D. Togawa ${ }^{1}$, S. Mori ${ }^{1}$, K. Yamazaki ${ }^{1}{ }^{1}$ Nara Hospital, Kindai University, Orthopaedic Surgery and Rheumatology, Ikoma City, Japan

Background: In $20-30 \%$ of rheumatoid arthritis (RA) patients, the first biologic disease-modifying antirheumatic drugs (bDMARDs) (generally tumour necrosis factor inhibitors (TNFis)) is ineffective, and among the patients who do respond to therapy, $20 \%$ is faced with secondary ineffectiveness within the first 2 years of treatment [1]. In practice, when refractory RA is present, of which the definition implies previous use of at least two bDMARDs (generally TNFis), the next treatment choice often made is a bDMARD of another class (non-TNFis) [2]. On the other hand, patients who are inadequately responding to bDMARDs need new treatment options because subsequent bDMARD treatment reduces their response [3]. Janus Kinase inhibitors (JAKis) are the first targeted synthetic DMARDs (tsDMARD) licensed for the treatment of RA with comparable efficacy to bDMARDs. Unlike the single cytokine targeting approach of bDMARDs, JAKis are specifically designed to inhibit intracellular signalling molecules common to the receptors of multiple inflammatory cytokines implicated in RA pathogenesis. Objectives: Difficult-to-treat (D2T) RA is defined as refractory to two or more $\mathrm{b} / \mathrm{ts}$ DMARDs with different mechanisms of action, with active and progressive disease, as published by Eular(4). We evaluated real world efficacy of approved JAKis and factors that may help to continue them in patients with D2T RA.

Methods: Patients who had inadequate response to two or more bDMARDs (including both TNFis and non-TNFis) at our hospital by December 2019 were defined as D2T RA, and patients who switched to JAKis were retrospectively investigated. The drug retention rate was determined by Kaplan-Meier method and the difference was tested by Logrank test. Multiple regression analysis was used as the statistical method to predict continuation of JAKis for more than 1 year with patient background (age, gender, during the disease, number of bDMARDs used, with or without methotrexate and/or glucocorticoids, disease activity score assessing 28 joints using erythrocyte sedimentation rate' presence of rheumatoid factor/anti-CCP antibody, matrix metalloproteinase 3 value, Health Assessment Questionnaire disability index) at the time of initiation as an explanatory variable. Results: A total of 915 bDMARDs had been administered to 394 RA patients The retention rate of bDMARDs and the number of bDMARDs used were $89.3 \%$ and 1.48 bDMARDs at 1 year, $67.7 \%$ and 2.27 bDMARDs at 5 years, and $52.0 \%$ and 3.15 bDMARDs at 10 years, respectively. The retention rate of JAKis at 1 year was $60.2 \%$ in 65 patients with tofacitinib (TOF) and $67.2 \%$ in 70 patients with baricitinib (BAR) $(P=0.38)$. Among them, the drug retention rate in D2T RA patients was $50.8 \%$ in 38 TOF patients and $66.3 \%$ in 35 BAR patients with no significant difference $(P=0.30)$. There were no patient background factors that significantly predicted continuation at 1 year for any JAKis.

Conclusion: Despite the limited number of patients and the retrospective nature of the study, TOF and BAR were shown to be effective options for D2T RA, regardless of patient background such as disease activity or number of bDMARDs used. Other JAKis and switches between JAKis need to be investigated in the future.

\section{REFERENCES:}

[1] Schaeverbeke T, Truchetet ME, Kostine M et al. Immunogenicity of biologic agents in rheumatoid arthritis patients: lessons for clinical practice. Rheumatology 2016;55:210_20.

[2] Smolen JS, Landewe R, Bijlsma J et al. EULAR recommendations for the management of rheumatoid arthritis with synthetic and biologica disease-modifying antirheumatic drugs: 2016 update. Ann Rheum Dis 2017;76:960_77. 
[3] Rendas-Baum R, Wallenstein GV, Koncz T et al. Evaluating the efficacy of sequential biologic therapies for rheumatoid arthritis patients with an inadequate response to tumor necrosis factor- $\alpha$ inhibitors. Arthritis Res Ther 2011;13:R25.

[4] Nagy G, et al. EULAR definition of difficult-to-treat rheumatoid arthritis. Ann Rheum Dis 2021;80:31-35. doi:10.1136/annrheumdis-2020-217344.

Disclosure of Interests: None declared

DOI: 10.1136/annrheumdis-2021-eular.542

\section{\begin{tabular}{|l|l}
\hline POS0089 AZD9567 VERSUS PREDNISOLONE IN PATIENTS \\
\hline
\end{tabular} WITH ACTIVE RHEUMATOID ARTHRITIS: A PHASE 2A, RANDOMISED, DOUBLE-BLIND, PARALLEL-GROUP EFFICACY AND SAFETY STUDY}

J. M. Van Laar ${ }^{1}$, A. Lei ${ }^{2}$, M. Safy-Khan ${ }^{1}$, J. Almquist ${ }^{3}$, C. Astbury ${ }^{4}$, M. Belvisi ${ }^{5}$, A. Platt ${ }^{6}$, S. Prothon ${ }^{3}$, S. Samuelsson ${ }^{7}$, P. Svanberg ${ }^{8}$, C. Keen ${ }^{7}$ on behalf of The SEMRA Study Group. ${ }^{1}$ University Medical Center Utrecht, Division of Internal Medicine and Dermatology, Department of Rheumatology \& Clinical Immunology, Utrecht, Netherlands; ${ }^{2}$ AstraZeneca, Patient Safety, Respiratory \& Immunology, Chief Medical Office, R\&D, Barcelona, Spain; ${ }^{3}$ AstraZeneca, Clinical Pharmacology and Quantitative Pharmacology, Clinical Pharmacology \& Safety Sciences, $R \& D$, Gothenburg, Sweden; ${ }^{4}$ AstraZeneca, Research and Early Development, Respiratory \& Immunology, BioPharmaceuticals R\&D, Cambridge, United Kingdom; ${ }^{5}$ AstraZeneca, Research and Early Development, Respiratory \& Immunology, BioPharmaceuticals R\&D, Gothenburg, Sweden; ${ }^{6}$ AstraZeneca, Translational Science and Experimental Medicine, Research and Early Development, Respiratory \& Immunology, BioPharmaceuticals R\&D, Cambridge, United Kingdom; ${ }^{7}$ AstraZeneca, Clinical Development, Research and Early Development, Respiratory \& Immunology, BioPharmaceuticals R\&D, Gothenburg, Sweden; ${ }^{8}$ AstraZeneca, Drug Metabolism and Pharmacokinetics, Research and Early Development, Respiratory \& Immunology, BioPharmaceuticals R\&D, Gothenburg, Sweden

Background: Oral corticosteroids such as prednisolone are potent anti-inflammatory drugs but their use is limited by side effects caused by unwanted actions on the glucocorticoid receptor (GR), such as increased insulin resistance, and off-target actions on the mineralocorticoid receptor (MR) that disrupt electrolyte balance and increase water retention. AZD9567 is an oral, selective, non-steroidal glucocorticoid receptor modulator being developed to treat inflammatory diseases. Pre-clinical and phase 1 clinical data indicate that AZD9567 is the first GR modulator with an improved efficacy-dysglycaemic side effect profile versus prednisolone.

Objectives: To compare the efficacy, safety and tolerability of AZD9567 with prednisolone in patients with active rheumatoid arthritis (RA), at doses with predicted equivalent anti-inflammatory activity.

Methods: In this phase 2a, randomised, double-blind, parallel-group, multicentre study in RA patients with DAS28-CRP $\geq 3.2$ despite stable treatment with conventional disease-modifying anti-rheumatic therapies (NCT03368235), patients were randomised $1: 1$ to AZD9567 $40 \mathrm{mg}$ or prednisolone $20 \mathrm{mg}$ orally once daily for 14 days. The primary endpoint was change from baseline in DAS28-CRP at day 15. Secondary outcomes included components of DAS28-CRP, TJC68,

Table 1. Change from baseline to day 15 in clinical disease activity measures.

\begin{tabular}{|c|c|c|c|c|c|c|c|}
\hline & \multicolumn{2}{|c|}{$\begin{array}{l}\text { AZD9567 } \\
(n=11)\end{array}$} & \multicolumn{2}{|c|}{$\begin{array}{l}\text { Prednisolone } \\
\qquad(n=10)\end{array}$} & \multicolumn{3}{|c|}{$\begin{array}{c}\text { Comparison } \\
\text { (AZD9567 - prednisolone) }\end{array}$} \\
\hline & $\begin{array}{l}\text { CFB } \\
\text { (SE) }\end{array}$ & $95 \% \mathrm{Cl}$ & $\begin{array}{l}\text { LSM CFB } \\
\text { (SE) }\end{array}$ & $95 \% \mathrm{Cl}$ & $\begin{array}{l}\text { LSMD } \\
\text { (SE) }\end{array}$ & $95 \% \mathrm{Cl}$ & $\begin{array}{c}p \\
\text { value }\end{array}$ \\
\hline $\begin{array}{l}\text { DAS28-CRP } \\
\text { score }\end{array}$ & $\begin{array}{l}-1.93 \\
(0.35)\end{array}$ & $-2.66,-1.21$ & $\begin{array}{l}-2.40 \\
(0.34)\end{array}$ & $-3.11,-1.70$ & $\begin{array}{l}0.47 \\
(0.46)\end{array}$ & $-0.49,1.43$ & 0.315 \\
\hline TJC28 score & $\begin{array}{l}-6.12 \\
(1.25)\end{array}$ & $-8.76,-3.49$ & $\begin{array}{l}-6.07 \\
(1.21)\end{array}$ & $-8.61,-3.52$ & $\begin{array}{l}-0.05 \\
(1.60)\end{array}$ & $-3.43,3.32$ & 0.973 \\
\hline SJC28 score & $\begin{array}{l}-5.14 \\
(0.65)\end{array}$ & $-6.51,-3.76$ & $\begin{array}{l}-5.40 \\
(0.63)\end{array}$ & $-6.73,-4.08$ & $\begin{array}{l}0.26 \\
(0.84)\end{array}$ & $-1.50,2.03$ & 0.757 \\
\hline GH score & $\begin{array}{c}-27.7 \\
(7.3)\end{array}$ & $-42.8,-12.5$ & $\begin{array}{c}-37.4 \\
(7.1)\end{array}$ & $-52.3,-22.6$ & $\begin{array}{c}9.8 \\
(9.7)\end{array}$ & $-10.5,30.1$ & 0.325 \\
\hline CRP, mg/L & $\begin{array}{l}-10.8 \\
(2.4)\end{array}$ & $-15.9,-5.8$ & $\begin{array}{l}-15.6 \\
(2.5)\end{array}$ & $-20.9,-10.3$ & $\begin{array}{l}4.8 \\
(3.5)\end{array}$ & $-2.5,12.0$ & 0.187 \\
\hline TJC68 score & $\begin{array}{l}-9.02 \\
(2.46)\end{array}$ & $-14.21,-3.82$ & $\begin{array}{l}-7.90 \\
(2.36)\end{array}$ & $-12.88,-2.91$ & $\begin{array}{l}-1.12 \\
(3.12)\end{array}$ & $-7.69,5.46$ & 0.724 \\
\hline SJC66 score & $\begin{array}{l}-6.24 \\
(0.89)\end{array}$ & $-8.13,-4.36$ & $\begin{array}{l}-6.66 \\
(0.86)\end{array}$ & $-8.48,-4.85$ & $\begin{array}{l}0.42 \\
(1.14)\end{array}$ & $-1.98,2.81$ & 0.717 \\
\hline
\end{tabular}

( GH, global health; LSM(D), least-squares mean (difference); SJC, swollen joint count; TJC, tender joint count.
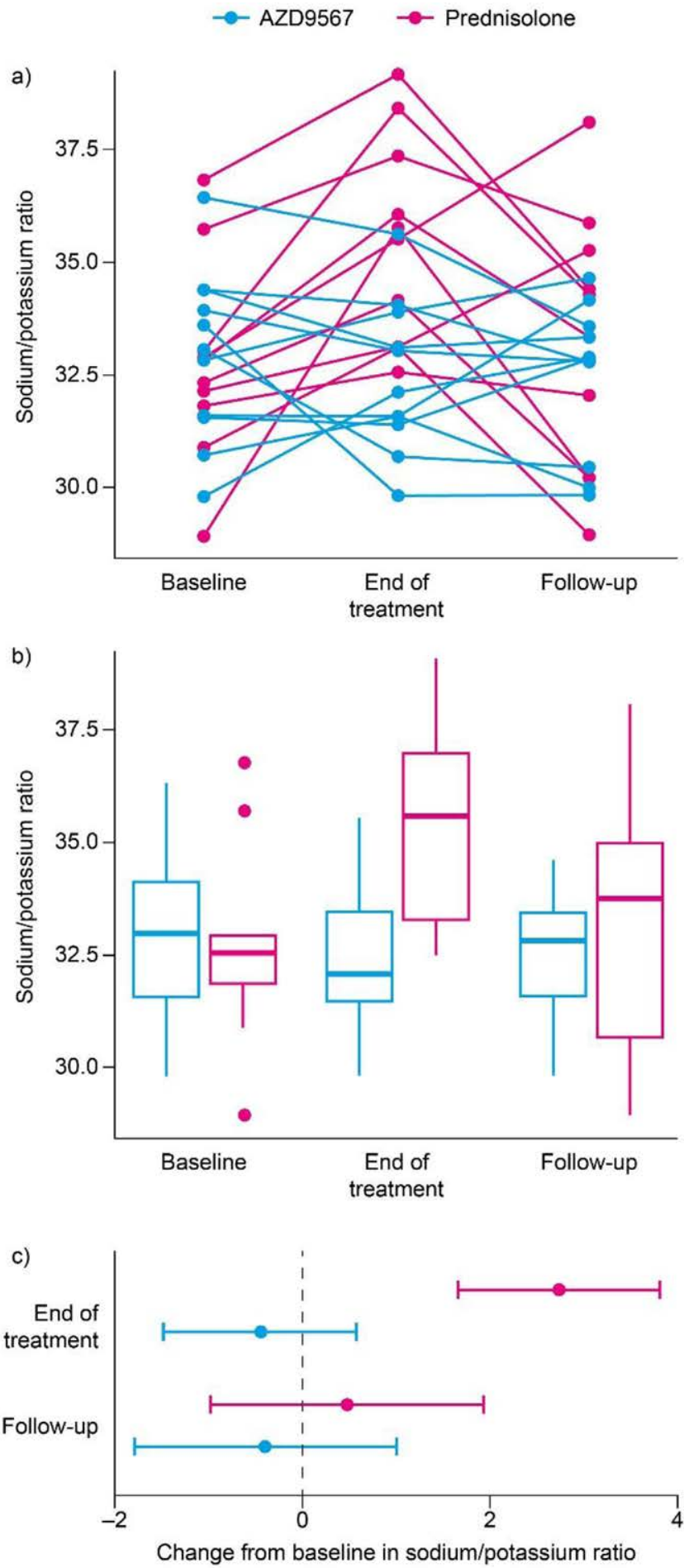

Figure. Morning serum sodium/potassium ratio with AZD9567 or prednisolone, under fasting conditions. a) Individual-level data. b) Box-and-whisker plots showing median, interquartile range and range. c) Change from baseline to day 15 (i.e. end of treatment; adjusted for baseline values) with $95 \%$ confidence intervals. Follow-up was approximately 14 days after the last dose.

SJC66, ACR response (ACR20, ACR50, ACR70) and safety outcomes, including serum electrolytes.

Results: All 21 randomised patients (AZD9567, $n=11$; prednisolone, $n=10$ ) completed the study. There was a slight imbalance between the treatment groups at baseline, with higher age (mean \pm SD: $64.5 \pm 8.4$ vs $55.5 \pm 13.6$ years), more women (8 vs 5 ) and greater disease severity (DAS28-CRP, mean \pm SD: $5.26 \pm$ 